\title{
Pengaruh Inflasi, Penagihan Pajak dan Penyuluhan Pajak terhadap Penerimaan Pajak Penghasilan
}

\author{
Putri Nadia ${ }^{1}$, Rayna Kartika ${ }^{2}$ \\ ${ }^{1,2}$ Fakultas Ekonomi Pascasarjana Akuntansi, Universitas Andalas, Indonesia \\ Correspondence email: putrinadiaunand@gmail.com
}

\begin{abstract}
Abstrak. Penelitian ini bertujuan menguji pengaruh Inflasi, Penagihan Pajak, dan Penyuluhan Pajak terhadap Penerimaan Pajak Penghasilan. Penelitian ini mengunakan data laporan yang didokumentasi dari kantor pelayanan pajak Kecamatan Tampan Pekanbaru dan Badan Pusat Statistik Pekanbaru berupa data Inflasi, kegiatan penagihan, dan penyuluhan pajak selama 3 tahun (Januari 2017 - Desember 2019). Data dianalisis menggunakan analisis Regresi Berganda. Hasil penelitian menunjukan bahwa variabel inflasi dan penyuluhan pajak berpengaruh signifikan terhadap penerimaan pajak penghasilan. Di sisi lain, variabel penagihan pajak tidak berpengaruh signifikan terhadap penerimaan pajak penghasilan. Temuan ini menggaris bawahi penagihan pajak penghasilan tidak memiliki pengaruh signifikan terhadap penerimaan pajak penghasilan ini disebabkan penagihan pajak dilakukan pada semua kalangan yang memiliki tunggakan pajak. Sebagai kontribusi bahwa dalam penerbitan Surat Tagihan Pajak(STP), fiskus dapat memfokuskan penerbitan STP kepada wajib pajak yang memiliki tunggakan yang jumlahnya besar, agar penerimaan pajak penghasilan dapat meningkat lebih cepat. karena semakin banyak STP yang dikeluarkan membuktikan bahwa kegiatan penagihan pajak belum tentu dapat berjalan secara efektif.
\end{abstract}

Kata kunci: Penerimaan Pajak Penghasilan; Inflasi; Penagihan Pajak; Penyuluhan Pajak.

Abstract. This study aims to examine the effect of inflation, tax collection, and tax education on income tax revenue. This study uses report data documented from the Tampan subdistrict tax office in Pekanbaru and the Central Statistics Agency of Pekanbaru in the form of inflation data, billing activities, and tax counseling for 3 years (January 2017 - December 2019). Data were analyzed using Multiple Regression analysis. The results showed that inflation and tax counseling variables significantly influence income tax revenue. On the other hand, the tax collection variable has no significant effect on income tax revenue. This finding underlines the collection of income tax does not have a significant effect on income tax revenue is due to tax collection carried out on all people who have tax arrears. As a contribution that in the issuance of Tax Collection Letter (STP), the tax authorities can focus the issuance of STP to taxpayers who have large amounts of arrears, so that income tax revenue can increase faster. because more and more STPs issued to prove that tax collection activities may not be able to run effectively.

Keywords: Income tax revenue; Inflation; Tax collection; Tax Education

\section{PENDAHULUAN}

Pemerintah menggunakan sistem pajak sebagai instrumen kebijakan untuk mencapai berbagai tujuan, di antaranya adalah redistribusi pendapatan, stabilisasi ekonomi, penyediaan barang publik, dan mendorong pertumbuhan ekonomi (Amir, Asafu-Adjaye \& Ducpham, 2013). Kombinasi dan pentingnya tujuan ini bervariasi untuk setiap negara, dan biasanya tergantung pada latar belakang politik dan ekonomi masing-masing (Amir et al. 2013). Di Indonesia Pajak sebagai sumber utama penerimaan negara yang menyumbang sekitar $70 \%$ dari seluruh penerimaan negara (Nurlaela, 2018). Dengan demikian, tanpa penerimaan pajak, sebagian besar kegiatan negara seperti belanja pegawai sampai dengan pembiayaan berbagai proyek pembangunan akan sulit untuk dilaksanakan (Yunita,Ratnawati, \& Rusli, 2017). Semakin banyak pajak yang diterima negara akan menambah pendapatan negara, maka diasumsikan semakin banyak infrastruktur atau fasilitas yang akan dibangun demi menciptakan kesejahteraan masyarakat (Pranata \& Setiawan, 2015). Penerimaan pajak dalam negeri terbagi dalam beberapa sektor seperti, Pajak Penghasilan (PPh), Pajak Pertambahan Nilai (PPN),
Pajak Bumi Bangunan (PBB), cukai dan pajak lainnya. Salah satu sektor perpajakan yang memiliki kontribusi tertinggi terhadap pendapatan negara yaitu pajak penghasilan (Pratama, Dwiatmanto, \& Agusti, 2015).

Pemerintah mewajibkan masyarakatnya untuk membayar pajak, hal ini sesuai dengan ketentuan perpajakan KEP-DJP No.161/PJ/2001 yang menyatakan setiap badan atau orang yang berada di indonesia apabila telah memenuhi kewajiban untuk memiliki Nomor Pokok Wajib Pajak (NPWP), maka kepadanya diwajibkan menjalankan kewajibannya untuk menghitung, memperhitungkan, menyetor dan melaporkan pajak, begitu pula bendaharawan sebagai pemotong dan pemungut pajak.

Penagihan pajak dapat dilakukan salah satunya melalui penagihan pajak kepada wajib pajak oleh fiskus, ketika fiskus sudah melakukan peneguran serta memperingatkan wajib pajak agar memenuhi kewajibannya, namun wajib pajak tersebut juga tidak mau memenuhi kewajiban perpajakannya, maka fiskus harus melakukan penagihan pajak dengan cara melaksanakan penagihan seketika dan sekaligus memberitahukan surat paksa, mengusulkan pencegahan, 
melaksanakan penyitaan, melaksanakan penyanderaan dan menjual barang yang telah disita (Rusdji, 2004). Hal itu terpaksa dilakukan fiskus untuk menyadarkan masyarakat bahwa pajak itu sangat penting, dengan adanya tindakan tersebut maka penerimaan pajak suatu negara khususnya pajak penghasilan akan meningkat.

Faktor penunjang penerimaan pajak penghasilan seperti membuat program penyuluhan perpajakan diperlukan agar masyarakat menyadari pentingnya membayar pajak. Kegiatan penyuluhan pajak tersebut juga dapat memudahkan fiskus dalam melakukan penagihan pajak kepada masyarakat yang terlibat dalam wajib pajak. Penyuluhan bisa dilakukan secara langsung dari tempat ke tempat, melakukan seminar atau perkumpulan atau secara tidak langsung melalui media cetak atau online. Tujuan penyuluhan perpajakan dilaksanakan sebagai langkah Dirjen pajak untuk memberikan pengertian, informasi dan pembinaan kepada masyarakat mengenai segala sesuatu yang berhubungan dengan perundang - undangan perpajakan. Harapan dirjen pajak setelah melakukan kegiatan penyuluhan pajak ini agar masyarakat paham dan mengerti bahwa pembayaran pajak merupakan suatu kewajiban yang diharuskan.

Masyarakat sangat mengharapkan peranan pemerintah dalam memperhatikan kebutuhannya, seperti pendidikan, kesehatan, transportasi dan lain sebagainya. Namun, kenyataannya masih banyak masyarakat yang belum taat membayar pajak karena minimnya informasi mengenai manfaat pajak serta kurangnya perhatian masyarakat mengenai kewajiban perpajakan, untuk itu pemerintah perlu melakukan perbaikan dalam faktor eksternal yang menyangkut masalah lingkungan ekonomi salah satunya inflasi menjadi masalah penerimaan pajak penghasilan suatu negara. Ketika inflasi terjadi maka harga-harga secara keseluruhan akan naik karena disebabkan meningkatnya jumlah uang yang beredar. Hal ini tentu akan menambah beban perusahaan dalam memproduksi suatu barang karena meningkatnya jumlah biaya produksi yang dikeluarkan seperti biaya bahan baku, ditambah dengan permintaan serikat buruh yang meminta peningkatan gaji, dalam meminimalisir pengeluaran tersebut maka salah satu alternatif perusahaan yaitu memutuskan hubungan pekerjaan dengan karyawannya hal ini tentu menyebabkan banyak karyawan yang kehilangan penghasilan.

Tujuan penelitian ini adalah untuk menguji secara empiris pengaruh dari Inflasi, penerimaan, dan penyuluhan pajak terhadap penerimaan pajak penghasilan. Penelitian ini berkontribusi memberikan bukti empiris, inflasi dapat mempengaruhi penerimaan pajak dan penyuluhan pajak berpengaruh positif terhadap penerimaan pajak. Penerimaan pajak penghasilan dalam penelitian ini menjelaskan bahwa kegiatan penagihan pajak tidak memiliki pengaruh signifikan terhadap penerimaan pajak penghasilan yang berarti pihak Fiskus tidak memiliki batasan dalam penerbitan Surat Tagihan Pajak (STP) seperti memfokuskan penerbitan STP kepada wajib pajak yang memiliki tunggakan yang jumlahnya besar, agar penerimaan pajak penghasilan dapat meningkat lebih cepat. Semakin banyak STP yang dikeluarkan membuktikan belum tentu membuat kegiatan penagihan pajak belum berjalan secara efektif.

Teori keynes menyatakan bahwa inflasi terjadi karena masyarakat hidup diluar batas kemampuan ekonominya dengan memfokuskan bagaimana perebutan rezeki antar golongan masyarakat bisa menimbulkan permintaan lebih besar dari jumlah barang yang tersedia (Putong, 2009). Hubungan teori tersebut dengan penelitian ini bahwa diperlukan peranan pemerintah dalam mengatasi masalah inflasi tersebut seperti mengendalikan kebijakan pajak guna menjaga kelancaran penerimaan pajak penghasilan. Salah satu fenomena yang dialami oleh perekonomian suatu negara adalah faktor inflasi yang cenderung fluktuatif (Pratama, 2016). Inflasi merupakan suatu keadaan dimana jumlah permintaan lebih besar dari jumlah penawaran. Ferdiawan (2015) menyatakan inflasi juga mengakibatkan menurunnya nilai mata uang suatu negara dan melemahkan daya beli terhadap uang yang telah diinvestasikan. Disamping itu, inflasi yang tinggi juga bisa mengurangi tingkat pendapatan riil yang diperoleh investor dari investasinya (Kewal, 2015). Pratama (2016) menegaskan inflasi memiliki pengaruh negatif terhadap penerimaan pajak penghasilan. Kemudian, Ferdiawan (2015) menemukan bukti inflasi berpengaruh terhadap penerimaan pajak penghasilan. Berlandaskan hal tersebut maka hipotesis 1 dirumuskan sebagai berikut:

H1: Inflasi berpengaruh terhadap penerimaan pajak penghasilan

Resmi (2011) menyatakan bahwa pembagian beban pajak kepada rakyat didasarkan pada kepentingan masing-masing orang dalam tugas-tugas pemerintah, termasuk perlindungan atau jiwa orang-orang itu beserta harta bendanya, maka semakin besar kepentingan seseorang terhadap negara, makin tinggi pajak yang harus dibayar. Hubungan teori tersebut dalam penelitian ini bahwa masyarakat harus memenuhi kewajiban perpajakannya sesuai dengan besar kebutuhannya terhadap pemerintah, agar penerimaan pajak penghasilan stabil. Penagihan pajak merupakan suatu kegiatan yang dilakukan oleh direktorat jendral pajak apabila wajib pajak memiliki tanggungan pajak yang masih harus dibayar baik secara pasif maupun aktif. Penagihan pajak pasif adalah penagihan yang dilakukan sebelum tanggal jatuh tempo melalui himbauan lewat surat, telepon atau media lainnya, sedangkan penagihan pajak aktif adalah penagihan pajak yang dilakukan setelah jatuh tempo melalui penerbitan surat teguran, surat paksa, surat perintah melakukan penyitaan sampai dengan 
pelaksanaan penjualan barang sita melalui lelang (Paseleng et al., 2013). Berdasarkan hasil penelitian yang dilakukan Sari (2015), penagihan pajak berpengaruh signifikan terhadap peningkatan penerimaan pajak. Kemudian, penelitian yang dilakukan oleh Paseleng et al. (2013) dan Madjid (2015) yang menyatakan bahwa ada hubungan antara efektivitas dan kontribusi penagihan pajak. Berlandaskan hal tersebut maka hipotesis 2 dirumuskan sebagai berikut:

H2 : Penagihan pajak berpengaruh terhadap penerimaan pajak penghasilan

Teori bakti mengindikasi bahwa karena sifat suatu negara maka timbullah hak mutlak untuk memungut pajak, orang - orang tidaklah berdiri sendiri, dengan tidak adanya persekutuan tidak akan ada individu (Resmi, 2011). Hubungan teori tersebut dalam penelitian ini bahwa masyarakat yang berbakti ialah masyarakat yang taat akan pajaknya. Pihak fiskal harus memfokuskan kegiatan penyuluhan, agar meningkatkan sifat bakti terhadap masyarakat dalam memenuhi kewajiban perpajakannya. Tinggi rendahnya penerimaan pajak dapat dipengaruhi beberapa faktor, salah satu faktornya adalah kurangnya penyuluhan perpajakan kepada wajib pajak (Putriani \& Budiartha, 2016). Penyuluhan perpajakan dilakukan oleh petugas pajak untuk memberikan informasi agar wajib pajak memahami tata cara pembayaran pajak yang benar dan sesuai dengan peraturan perpajakan. Penyuluhan merupakan suatu bentuk pendidikan yang cara, bahan dan sarananya disesuaikan dengan keadaan, kebutuhan dan kepentingan sasaran (Rohmawati \& Rasmini, 2012). Berdasarkan penelitian yang dilakukan oleh Putriani dan Budiartha (2016), penyuluhan perpajakan berpengaruh pada penerimaan pajak penghasilan badan.
Berlandaskan hal tersebut maka hipotesis 3 dirumuskan sebagai berikut:

H3 : Penyuluhan pajak berpengaruh terhadap penerimaan pajak penghasilan

\section{METODE}

Penelitian ini mengunakan data skunder. Data yang diperoleh berasal dari dokumentasi Kantor Pelayanan Pajak Tampan Pekanbaru dan website resmi Badan Pusat Statistik (BPS) Pekanbaru selama 3 tahun (Januari 2017 - Desember 2019) secara bulanan sehingga diperoleh sampel dalam penelitian ini sebesar 36 buah data (3 tahun x 12 bulan). Data tersebut berupa data penerimaan pajak penghasilan pasal $25(\mathrm{Y})$, data kegiatan penyuluhan pajak (X3), data penerbitan SKP dari penagihan pajak (X2) serta data inflasi (X1) bulanan yang diterbitkan oleh badan pusat statistik pekanbaru melalui website resminya. Data dianalisis menggunakan analisis regresi berganda dengan menggunakan uji asumsi klasik berupa uji normalitas, uji multikolinieritas, uji heteroskedastisitas, dan uji autokorelasi serta menguji hipotesis menggunakan uji secara parsial ( $\mathrm{t}$ ), simultan (F) dan koefisien determinasi $\left(\mathrm{R}^{2}\right)$. Alat yang digunakan untuk membantu mengolah data dan menguji hipotesis tersebut menggunakan software berupa SPSS Versi 25.

\section{HASIL DAN PEMBAHASAN}

Hasil uji Statistik Deskriptif pada penelitian in bisa dilihat pada Tabel 1. Tabel 1 menunjukkan bahwa terdapat penyebaran data yang baik karena pada variabel penagihan pajak, penyuluhan pajak dan penerimaan pajak penghasilan memiliki rata - rata lebih tinggi dibanding nilai standar deviasinya. Namun berbanding terbalik pada variabel Inflasi yang rata - ratanya lebih rendah dari nilai standar deviasinya.

Tabel 1. Hasil Statistik Deskriptif

\begin{tabular}{llllll}
\hline & $\mathrm{N}$ & Minimum & Maximum & Mean & Std. Deviation \\
\hline Inflasi & 36 & $-1,26$ & 1,46 & 0,3019 & 0,58691 \\
Penagihan Pajak & 36 & 16,08 & 22,26 & 20,0217 & 1,66541 \\
Penyuluhan Pajak & 36 & 0 & 4 & 2,61 & 0,994 \\
Penerimaan Pajak & 36 & 22,72 & 25,87 & 24,3714 & 0,54674 \\
\hline
\end{tabular}

Sumber: Data Penelitian, 2020

Model regresi yang baik adalah variabel terdistribusi normal atau mendekati normal. Uji Normalitas pada penelitian ini mengunakan uji statistik Kolmogorov-Smirnov Test. Hail uji Normalitas dapat dilihat pada tabel 2.

Tabel 2. Hasil Uji Normalitas

\begin{tabular}{lc}
\hline & Unstandardized Residual \\
\hline $\mathrm{N}$ & 36 \\
Test Statistic &, 093 \\
Asymp. Sig. (2-tailed) &, 200 \\
\hline
\end{tabular}

Sumber: Data Penelitian, 2020
Tabel 2 dapat dilihat bahwa asymp. sig. (2-tailed) bernilai 0.200 . hal ini menunjukkan bahwa nilai tersebut lebih besar dari taraf nyata $5 \%(0.200>0.05)$ sehingga dapat dinyatakan data penelitian terdistribusi normal.

Kriteria untuk menguji ada atau tidaknya korelasi dalam model regresi dengan melihat nilai tolerance dan Variance Inflation Factor (VIF). Uji Multikoleniaritas dapat dilihat berdasarkan nilai VIF dan nilai tolerance. Hasil uji dapat dilihat dari Tabel 3. 
Putri Nadia dan Rayna Kartika, Pengaruh Inflasi, Penagihan Pajak dan Penyuluhan Pajak terhadap Penerimaan Pajak Penghasilan

Tabel 3. Hasil Uji Multikolinearitas

\begin{tabular}{lcc}
\hline \multicolumn{1}{c}{ Model } & \multicolumn{2}{c}{ Collinearity Statistics } \\
& Tolerance & VIF \\
\hline (Constant) & & \\
Inflasi & 0,977 & 1,023 \\
Penagihan Pajak & 0,997 & 1,003 \\
Penyuluhan Pajak & 0,979 & 1,022 \\
\hline
\end{tabular}

a. Dependent Variabel: Penerimaan Pajak Penghasilan

Sumber: Data Penelitian, 2020

Berdasarkan Tabel 3 dapat disimpulkan bahwa semua variabel memiliki nilai tolerance lebih besar dari $0,10(>0.10)$ dan nilai VIF lebih kecil dari $10(<10)$ hal ini membuktikan bahwa semua variabel terbebas dari masalah multikolinearitas.

Peneliti menggunakan uji glejser yaitu dengan cara meregresikan antara variabel independen dengan nilai absolut residualnya (Ghozali, 2018). Jika nilai signifikansi antara variabel independen dengan absolute residual lebih dari 0,05 maka dapat disimpulkan bahwa tidak terjadi heteroskedastisistas (Ghozali, 2018). Hasil Uji Heteroskedastisitas dapat dilihat pada Tabel 4.

Tabel 4 Hasil Uji Heteroskedastisitas

\begin{tabular}{ll}
\hline \multicolumn{1}{c}{ Model } & Sig \\
\hline (Constant) & 0.319 \\
Inflasi & 0.534 \\
Penagihan Pajak & 0.144 \\
Penyuluhan Pajak & 0,529 \\
\hline
\end{tabular}

a. Dependent Variable : Penerimaan Pajak Penghasilan Sumber: Data Penelitian, 2020

Tabel 4 diperoleh nilai korelasi masing - masing variabel dengan menggunakan unstandardized residual dan nilai absolute residual pada variabel terikat (abs_res) memiliki nilai signifikansi lebih dari 0.05 $(>0.05)$ ini berarti bahwa semua variabel terbebas dari masalah heteroskedastisitas pada model regresi.

Model regresi yang baik biasanya tidak terjadi masalah autokorelasi. Untuk membuktikan model regresi terbebas dari autokorelasi yaitu dengan melihat nilai Durbin - Watson (DW), nilai DW yang diperoleh harus lebih besar dari DU dan lebih kecil dari 4-DU (DU < DW < 4-DU). Hasil uji autokorelasi dapat dilihat pada tabel 5 .

Tabel 5. Hasil Uji Autokorelasi

\begin{tabular}{cc}
\hline \multicolumn{2}{c}{ Model Summary } \\
\hline Model & Durbin-Watson \\
\hline 1 & 2,543 \\
\hline b. Dependent Variable: & Penerimaan Pajak Penghasilan
\end{tabular}

b. Dependent Variable: Penerimaan Pajak Penghasilan

Sumber: Data Penelitian, 2020

Tabel 5 menunjukkan nilai DW yang diperoleh 2.543 Hasil tersebut lebih besar dari nilai DU dimana berdasarkan tabel Durbin -Watson N=36, K=3 sebesar 1.29 dan lebih kecil dari $4-\mathrm{DU}(4-1.29=2.71)$. Hasil tersebut menunjukkan bahwa DU $<$ DW $<4-$ DU , sehingga dapat disimpulkan bahwa model regresi tidak terjadi autokorelasi.

Hasil Regresi Linear berganda pada penelitian ini dapat dilihat pada tabel 6 .

Tabel 6. Hasil Analisis Regresi Berganda

\begin{tabular}{lccc}
\hline \multicolumn{4}{c}{ Coefficients } \\
\hline \multicolumn{4}{c}{$\begin{array}{c}\text { Unstandardized } \\
\text { Coefficients }\end{array}$} \\
\hline B & $\mathrm{t}$ & Sig. \\
\hline (Constant) & 22,913 & 26,254 & 0.000 \\
Inflasi & 0,330 & 2,2723 & 0,010 \\
Penagihan Pajak & 0,022 & 0,520 & 0,607 \\
Penyuluhan & 0,352 & 4,937 & 0,000 \\
Pajak & & & \\
\hline
\end{tabular}

a. Dependent Variabel: Penerimaan Pajak Penghasilan Sumber: Data Penelitian, 2020

Tabel 6 diperoleh persamaan regresi linier berganda nya sebagai berikut:

$\mathrm{Y}=22.913+0.330 \mathrm{X}_{1}+0.022 \mathrm{X}_{2}+0.352 \mathrm{X}_{3}$

Nilai konstanta (a) adalah 22.913. artinya jika inflasi, penagihan pajak, dan Penyuluhan pajak nilainya adalah 0 maka tingkat penerimaan pajak penghasilan nilainya negatif, yaitu 22.913. Koefisien regresi variabel inflasi $\left(b_{1}\right)$ bernilai positif, yaitu 0.330 maka setiap peningkatan inflasi sebesar 1, penerimaan pajak penghasilan juga akan meningkat sebesar 0.330 dengan asumsi bahwa variabel bebas lainnya bernilai konstan. Penagihan pajak $\left(b_{2}\right)$ bernilai positif yaitu 0.022 maka setiap peningkatan penagihan pajak sebesar 1, penerimaan pajak penghasilan juga akan meningkat sebesar 0.022 dengan asumsi bahwa variabel bebas lainnya bernilai konstan. Penyuluhan pajak $\left(b_{3}\right)$ bernilai positif, yaitu 0.352 maka setiap peningkatan penyuluhan pajak sebesar 1, penerimaan pajak penghasilan juga akan meningkat sebesar 0.352 dengan asumsi bahwa semua variabel bebas lainnya bernilai konstan. Kemudian, Hasil Uji $F$ untuk pengujian variabel secara bersama-sama dapat dilihat pada tabel 7 .

Tabel 7. Hasil Uji F

\begin{tabular}{lccl}
\hline \multicolumn{4}{c}{ ANOVA } \\
\hline Model & \multicolumn{2}{c}{ F } & Sig. \\
Regression & 9,595 & 0,000 & \\
\hline
\end{tabular}

a. Dependent Variabel: Penerimaan Pajak Penghasilan

b. Predictors: (Constant), Penyuluhan Pajak, Penagihan

Pahak, Inflasi

Sumber: Data Penelitian, 2020

Tabel 7 memiliki nilai $\mathrm{F}$ hitung sebesar 9.595 dan $\mathrm{F}$ tabel sebesar 2.901 artinya $\mathrm{F}$ hitung $>\mathrm{F}$ tabel $(9.595>2.922)$ maka H0 di tolak. Jadi dapat disimpulkan bahwa inflasi, penagihan pajak, dan penyuluhan pajak secara bersama - sama berpengaruh 
terhadap penerimaan pajak penghasilan. Selanjutnya, Hasil Koefisien Determinasi dapat dilihat pada Tabel 8.

Tabel 8. Hasil Koefisien Determinasi

\begin{tabular}{lc}
\hline \multicolumn{2}{c}{ Model Summary } \\
\hline$R$ &, $688^{\mathrm{a}}$ \\
$R$ Square & 0,474 \\
Adjusted $R$ Square & 0,424 \\
Std. Error of the Estimate & 0,41488 \\
\hline
\end{tabular}

a. Predictors: (Constant), Penyuluhan Pajak, Penagihan

Pajak, Inflasi

Sumber: Data Penelitian, 2020

Tabel 8 diatas menunjukkan nilai R Square yang telah disesuaikan (Adjusted $R$ Square) sebesar 0.424 ini berarti sumbangan pengaruh variabel independen terhadap variabel dependen sebesar $42.4 \%$, sedangkan sisanya dipengaruhi oleh variabel lain yang tidak dimasukkan dalam model ini.

Hipotesis 1 memprediksi bahwa Inflasi memiliki pengaruh terhadap Penerimaan pajak Penghasilan. Tabel 6 Menunjukkan signifikansi Variabel inflasi menunujukkan nilai lebih kecil dari taraf nyata $(0.010<$ 0.05) artinya inflasi secara parsial berpengaruh signifikan terhadap penerimaan pajak penghasilan. Selain itu koefisien variabel inflasi sebesar 0.330 menunjukkan bahwa inflasi dan penerimaan pajak penghasilan memiliki hubungan positif. Hasil ini mendukung penelitian yang dilakukan Ferdiawan et al. (2015) yang menyatakan bahwa inflasi berpengaruh terhadap penerimaan pajak penghasilan. Namun, hal ini bertolak belakang terhadap penelitian yang dilakukan Pratama et al. (2016) yang mengatakan bahwa inflasi tidak berpengaruh terhadap penerimaan pajak penghasilan.

Hipotesis 2 menyatakan bahwa penagihan pajak berpengaruh terhadap penerimaan pajak Tabel 6 Menunjukkan nilai signifikansi variabel penagihan pajak menunjukkan nilai lebih besar dibanding tarif nyata $(0.607>0.05)$ yang berarti bahwa penagihan pajak tidak berpengaruh secara signifikan terhadap penerimaan pajak penghasilan. Namun koefisien variabel penagihan pajak sebesar 0.022 menunjukkan bahwa penagihan pajak memiliki pengaruh yang positif terhadap penerimaan pajak penghasilan. Hasil penelitian ini bertolak belakang dengan penelitian yang dilakukan Sari (2015) yang menyatakan bahwa penagihan pajak berpengaruh terhadap penerimaan pajak penghasilan. Hal ini disebabkan penagihan pajak dilakukan pada semua kalangan yang memiliki tunggakan pajak. Hal ini mengidikasi bahwa banyaknya STP yang dikeluarkan karena penagihan yang dilakukan tidak di fokuskan kepada wajib pajak yang memiliki tunggakan pajak lebih besar.

Hipotesis 3 menyatakan bahwa penyuluhan pajak berpengaruh terhadap penerimaan pajak Tabel 6 Menunjukkan nilai signifikansi lebih kecil dari taraf nyata $0.05 \%(0.000<0.05)$ ini berarti bahwa penyuluhan pajak berpengaruh signifikan terhadap penerimaan pajak penghasilan. Selain itu koefisien variabel penyuluhan pajak sebesar 0.352 menunjukkan bahwa penyuluhan pajak dan penerimaan pajak penghasilan memiliki hubungan positif. Hasil penelitian ini mendukung pembahasan dari peneliti terdahulu, penelitian yang dilakukan Putriani \& Budiartha (2016) yang menyatakan bahwa penyuluhan pajak berpengaruh secara parsial terhadap penerimaan pajak penghasilan.

\section{SIMPULAN}

Penelitian ini menguji pengaruh Inflasi, Penerimaan Pajak, dan Penyuluhan Pajak terhadap penerimaan pajak. Berdasarkan hail regresi yang telah dilakukan diperolah hasil. Inflasi dan penyuluhan pajak berpengaruh secara signifikan terhadap penerimaan pajak penghasilan. Tinggi rendahnya inflasi dapat mempengaruhi penerimaan pajak dan kegiatan penyuluhan dilakukan bukan hanya untuk mengajak wajib pajak untuk memenuhi kewajiban perpajakannya, tetapi lebih memberikan edukasi kepada wajib pajak mengenai manfaat pajak tersebut, sehingga kegiatan penyuluhan pajak tersebut memberikan respon positif terhadap masyarakat. Sedangkan penagihan pajak tidak memiliki pengaruh terhadap penerimaan pajak penghasilan. Hal ini disebabkan penagihan pajak dilakukan pada semua kalangan yang memiliki tunggakan pajak. Hal ini mengidikasi bahwa banyaknya STP yang dikeluarkan karena penagihan yang dilakukan tidak di fokuskan kepada wajib pajak yang memiliki tunggakan pajak lebih besar.

Penelitian ini memiliki keterbatasan. Pertama, studi ini hanya melibatkan satu kantor KPP pelayanan pajak daerah tampan pekanbaru penelitian yang akan datang dapat memperluas lokasi. Terakhir, Penelitian ini hanya mempertimbangkan tahun penelitian yang akan datang dapat menambahkan periode waktu lebih dari 3 tahun, agar bisa lebih luas sehingga hasil yang didapatkan lebih akurat.

\section{DAFTAR PUSTAKA}

Amir, H., Asafu-Adjaye, J., \& Ducpham, T. (2013). The impact of the Indonesian income tax reform: A CGE analysis. Economic Modelling, 31, 492501. doi:10.1016/j.econmod.2012.12.018

Ferdiawan, M.A., Kertahadi, \& Jauhari, A. (2015). Pengaruh Tingkat Inflasi, Tingkat Suku Bunga Sertifikat Indonesia, dan Nilai Tukar Kurs Terhadap Penerimaan Pajak Penghasilan (Studi Pada Penerimaan Pajak Penghasilan Dalam Kurun Waktu 2005 - 2014). Jurnal Mahasiswa Perpajakan (JEJAK),5(2), 1-9.

Ghozali, I. (2018). Aplikasi Analisis Multivariate dengan Program IBM SPSS 25. Semarang: Badan Penerbit Universitas Dipinegoro. 
Kewal, S.S. (2012). Pengaruh Inflasi, Suku Bunga, Kurs, Dan Pertumbuhan PDB Terhadap Indeks Harga Saham Gabungan. Jurnal Economia, 8(1), 53-64.

Madjid, O. \& Kalangi, L. (2015). Efektivitas Penagihan Pajak Dengan Surat Teguran dan Surat Paksa Terhadap Penerimaan Pajak Penghasilan Pada Kantor Pelayanan Pajak Pratama Bitung. Jurnal EMBA,3(4), 478-487.

Nurlaela, L. (2018). Pengaruh Self Assessment System dan sanksi perpajakan terhadap kepatuhan wajib pajak pada KPP Pratama Garut. Jurnal Wahana Akuntansi, 3(1), 1-11.

Putong, I. (2009). Economics, Pengantar Mikro dan Makro. Edisi Ketiga. Jakarta: Mitra Wacana Media.

Pranata, P. A., \& Setiawan, P. E. (2015). Pengaruh Sanksi Perpajakan, Kualitas Pelayanan Dan Kewajiban Moral Pada Kepatuhan Wajib Pajak. E-jurnal Akuntansi, 456-473.

Pratama, N.P, Dwiatmanto, \& Agusti, R.R. (2016).Pengaruh Inflasi, Pemeriksaan Pajak, dan Jumlah Wajib Pajak Terhadap Penerimaan Pajak Penghasilan (Studi Pada Kantor Pelayanan Pajak Pratama Malang Utara Periode 2010 Sampai 2014). Jurnal Mahasiswa Perpajakan (JEJAK), 8(1), 1-8.

Putriani, I.A.N \& Budiartha, I.K. 2016. Pengaruh Penyuluhan Perpajakan dan Pelayanan Fiskus Pada Penerimaan Pajak Penghasilan Badan. EJurnal Akuntansi, 14(1),79-90.

Paseleng, A, Poputra, A.T. \& Tangkuman, S.J. (2013). Efektivitas Penagihan Pajak Dengan Surat Teguran dan Surat Paksa Terhadap Penerimaan Pajak Penghasilan Pada Kantor Pelayanan Pajak Pratama Manado. Jurnal EMBA, 1(4), 2371-2381.

Resmi, Siti. (2011). Perpajakan: Teori dan Kasus. Edisi 6 Buku 1. Jakarta: Salemba Empat.

Rohmawati, A.N \& Rasmini, N.K. (2012). Pengaruh Kesadaran, Penyuluhan, Pelayanan, dan Sanksi Perpajakan Pada Kepatuhan Wajib Pajak Orang Pribadi. E-Jurnal Akuntansi, 1 (2), 1-17.

Sari, W.P. (2015). Pengaruh Kesadaran Wajib Pajak, Kegiatan Sosialisasi Perpajakan, Pemeriksaan Pajak Dan Jumlah Wajib Pajak Yang Terdaftar Terhadap Penerimaan Pajak Penghasilan Orang Pribadi Di KPP Pratama Pekanbaru Tampan. Jom FEKON, 2(2), 1-15.

Yunita, Ria., Rusnawati, V., \& Rusli, R. (2017). FaktorFaktor Yang Mempengaruhi Kemauan Melaksanakan Kewajiban Perpajakan Oleh Wajiv Pajak Orang Pribadi yang Melaksanakan Pekerjaan Bebas UMKM di Kota Pekanbaru (Studi Empiris KPP Pratama Pekanbaru Tampan).Jurnal Online Mahasiswa Fakultas Ekonomi Universitas Riau,4(1), 827-840. 